\title{
Multidimensional ROC model - rationalism, constructivism and optimism for strategic decision process in international environment
}

\author{
Padmakali Banerjee \\ Pro-Vice Chancellor \& Dean Academics, Amity University Haryana, Gurugram \\ Head \& Chair, Centre for BRICS Studies - AUH \\ Debasis Bhattacharya \\ Professor, Amity Business School, Amity University Haryana, Gurugram \\ Member, Centre for BRICS Studies - AUH
}

\section{Keywords}

Constructivism, International Relations, Interests, Optimism, Rationalism, Strategic Decisions

\begin{abstract}
Contemporary dynamics of global geopolitical and economic interdependence have been witnessing a growing trend of integration of various schools of thoughts with an endeavor of seeking interconnections for meaningful understanding of complex world developments. Inter-disciplinary research has become profoundly important for connecting with mainstream theoretical discussions across social sciences and humanities. Various traditional paradigms of international relations can be analyzed in a holistic manner by forging convergence, the so-called layering process, to explain politico-economic and business processes realistically. In this context it is imperative to comprehend two well-established mainstream international relations concepts of Rationalism and Constructivism by connecting the missing links that are ingrained in behavioral traits of political actors and their Optimism for making a holistic understanding of strategic political decision process.

This paper attempts to configure the interconnections between the powerful traditional theories pertaining to Rationalism and Constructivism in the domain of international relations with the dynamics of Optimism and psycho-dimensional behavioral traits of political actors. Analyzing the various tenets of theoretical foundations and their practical implications in international relations in an interdisciplinary framework, this paper introduces an innovative and adaptable multidimensional ROC (Rationalism Optimism - Constructivism) Model to meaningfully explain the complexities involved in strategic political decision process. The implications of the multidimensional ROC Model are expected to be profoundly impeccable in influencing the outcome of critical negotiations in strategic decision processes. Empirical analysis in the paper reflects the interface and synthesis of ROC tenets in a symbiotic manner most of the time in ensuring occurrence of positive outcome in strategic decisions.
\end{abstract}

Corresponding author: Padmakali Banerjee

Email addresses for the corresponding author: padmakali@ggn.amity.edu

First submission received: $19^{\text {th }}$ March 2019

Revised submission received: $9^{\text {th }}$ May 2019

Accepted: 16 $6^{\text {th }}$ April 2019

Introduction

The discipline of International Relations (IR) has been traditionally being plagued by a debate between rationalism and constructivism for quite some time. In recent years the terms of the debate itself has been under scrutiny because of the growing multidisciplinary implications of mainstream IR theories. If Rationalism is broadly regarded as a "methodological approach that may imply a philosophical position on what social explanation is and how it ought to work", then Constructivism is regarded as a "set of arguments about social explanation that may imply preferences over specific questions and methods of social inquiry" (Fearon and Wendt, 2002, p. 52). In this construct the role of optimism in behavioral attributes of political actors (having their implications on international institutions) can be integrated to 
build an overarching framework of strategic decision process in the ambit of mainstream International Relations.

\section{Ideation}

The paper explains that although there are differences between rationalism, constructivism and optimism there are also substantial areas of agreement. Moreover, where genuine differences exist, they are often complementarities rather than contradictions in a strict paradigmatic fashion. In recent years in the parlance of IR theoretical debate there is a great deal of perception that the divide between rationalism and constructivism is overstated and ill-founded (Risse, 2000). This is because despite the differences, there are areas of potential convergence which if ignored will considerably distort the paradigmatic analysis. Although one can outline some basic differences between the two constructs, just highlighting the differences implies a narrow and inappropriate theoretical review which grossly limits the true appreciation of the scope and extent of the interpretation. In fact, empirical evidence shows that there is significant overlapping and convergence between rationalism and constructivism. That being said from a cognitive and attitudinal standpoint the behavioral approach during strategic decision making in the arena of international politics and diplomacy cannot be overlooked especially in the context of global political and economic integration. Therefore, a new evolving perspective where behavioral traits and optimism of political leaders are being increasingly considered to be enmeshed with traditional rationalism and constructivism analysis, thereby providing a compelling focal point for a more meaningful and holistic understanding of strategic political decision process. Collectively the level of optimism of political actors plays a crucial role in driving their behavior towards viable decision making, its implementation and compliance. The paper attempts to highlight such inter-connections to formulate a robust approach of analyzing the trends of strategic policy making in the realm of international relations.

In international diplomacy political actors combine several modes of social interaction. Creation of new social realities, new norms about state actions and interventions, new beliefs among the public and policy makers are critical components in decision making process and policy outcomes (Finnemore, 2003). Therefore, it is not appropriate to overstate the distinction between rationalism and constructivism just on the characteristic feature based on the proposition that the former exhibits instrumentally motivated utility-maximizing action and the latter represents rule-guided behavior. Such a narrow interpretation on the cleavages creates intermediate spaces about human behavior unexplored thereby leaving the paradigmatic interpretation inadequately defined. Paying attention to human behavioral traits, cognitive perspectives and resilience is imperative in a multicultural diplomatic framework. Hence, there is an increasing trend towards making meaningful convergence between rationalism, constructivism, and behavioral optimism to rightfully explain strategic political decision process in the contemporary era of geopolitical interdependence. The multidimensional ROC Model introduced in the paper later corroborates this thesis. In fact, real life can be explained holistically when the two approaches rationalism and constructivism - portray complementary accounts of human behavior and attitudinal attributes in the overall domain of international politics. Moreover, in many cases there may be much to be gained by using the tools of one view to try to answer the questions which are often pertinent to the other view (Fearon and Wendt, 2002). Substantive arguments with respect to rationalism and constructivism while cutting across the traditional cleavages emphasize a synthetic approach in order to correctly explain the actual dynamics of international politics, where in political leaders' level of optimism and disposition of mind play a significant role (Wendt, 1999). This paper argues that just analyzing the differences between rationalism, constructivism and behavioral optimism is an inadequate exercise in exploring the empirical cases in true perspective. What is essential is to compare these theoretical constructs by highlighting not only the divergences but also the points of convergences in order to appreciate the synthetic view of rationalism, constructivism and optimism which is ultimately useful to discuss the empirical cases.

The paper attempts to deliberate on the three specific areas within the broader framework of Rationalism, Constructivism and Optimism Construct interpreted by the ROC Model: (1) materialism versus idealism; (2) logic of consequences versus logic of appropriateness; and (3) exogenous versus endogenous actors, interests and preferences. In each of these areas the paper highlights the points of 
divergences and convergences, and appreciates the interface between rationalism, constructivism and cognitive optimism. While doing so the paper discusses the empirical cases to justify the basic argument that the three paradigms are significantly interconnected as the outcome is influenced by multidisciplinary articulation.

\section{Rationalism, Constructivism and Optimism - Competency Decision Making in IR}

Rationalism is a paradigmatic approach that is characterized by strategic interactions and bargaining in which agents participate on the basis of their given identities and interests. The actors are rational egoistic entities aiming at utility maximization. This is the "realm of instrumental rationality whereby the goal of action is to maximize or optimize one's own interests and preferences" (Risse, 2000, p.3).

Constructivism is a theoretical foundation that is characterized by normative aspects of human consciousness in social life. It asserts that human behavior is primarily driven by ideational factors and normative rationality of doing the right thing rather than maximizing or optimizing their given preferences. The most important "ideational factors are widely shared or inter-subjective beliefs, which are not reducible to individuals" (Finnemore and Sikkink, 2001, p.391). The collective norms and understandings constitute the social identities of actors.

Optimism is the attitude and human behavioral attribute that strives for meaningful outcomes and success. This concept is related to cognitive dimensions of mental disposition, positive emotions and a sense of engagement that in turn drive individuals towards achieving positive outcomes (Banerjee, 2018). Behavioral perspectives of political actors can profoundly impact the strategic political decision process. In the domain of international relations the successful negotiations culminating into major treaties such as INF Treaty (Intermediate Range Nuclear Force Treaty) signed by then US President Ronald Reagan and Soviet Union Communist Party General Secretary Mikhail Gorbachev to diffuse tension during the peak of second phase of Cold War in the 1980s bears testimony of behavioral optimism coupled with positive alignment with a sense of meaningful engagement of world leaders.

Apart from international relations, in the realm of domestic politics such as a classic multiparty parliamentary democratic system in India, the successful passage of the Goods and Services Tax (GST) Bill in the Parliament of India in recent years was possible because of a deep sense of engagement with a spirit of optimism and positive mental alignment of diverse political parties even after a contentious debate (Bhattacharjee and Bhattacharya, 2018). On similar lines in domestic politics in a separated system of democracy, the passage of North American Free Trade Agreement (NAFTA) Bill was possible due to political consensus in an unconventional bipartisan manner that was propelled by a deep sense of engagement and positive mental alignment of policymakers having divergent ideological predisposition.

As evident in the deliberations stated so far, analytical interpretation of strategic decision making necessary requires convergence of the various theoretical constructs - Rationalism, Optimism and Constructivism - under a multidimensional framework in an increasingly dynamic era of global interdependence. While rational choice approach is instrumental and based on strategic interactions, utility maximization, mathematical modeling, deduction, and internal consistency, the "core assumptions of the model are ideal ones, originally made with a normative intent and that there are fundamental problems in the use of such models for explanations"(Stein, 1999, p.199). In recent years there is a growing consistency in the proposition that rationalist perceptions of utility are tightly bound up with normative perceptions of legitimacy, appropriateness coupled with optimism driving political actions. In contemporary era of global interdependence, it is essential to avoid artificially created "stark divisions between instrumental/strategic and moral forms of reasoning and action - since real political practices of argumentation and justification and legitimation draw in both together and in complex ways "(Hurrell and Macdonald, 2013, p.71). Separating the approaches or treating them as competing explanations is not only inappropriate but probably misguided since it misses the important question of how they are strategically intertwined and interdependent in decision making (Finnemore, 2003). The missing link is increasingly being analyzed in the form of a synthetic interpretation of optimism of political leaders' behavioral traits that work in tandem with traditional rationalism and constructivism. The psychological aspect of positive frame of mind i.e. optimism helps in trust building that, in turn, shape decision-making. 
Leaders more inclined to trust and positivity often are successful in negotiating and fulfilling commitments of internationally binding treaties (Haukkala, Watering and Vuorelma (2018). Thus, in reality, in contemporary multilateral diplomacy, the contours of strategic political decision process may be appropriately comprehended by a more robust multidimensional ROC (Rationalism-OptimismConstructivism) Model characterized by meaningful synergy between the three theoretical constructs. It is in this perspective that the innovative multidimensional ROC Model is introduced in this paper while envisaging the critical nature of complex strategic political decision making in a globalized multilateral political set up. The multidimensional ROC Model is exhibited below:

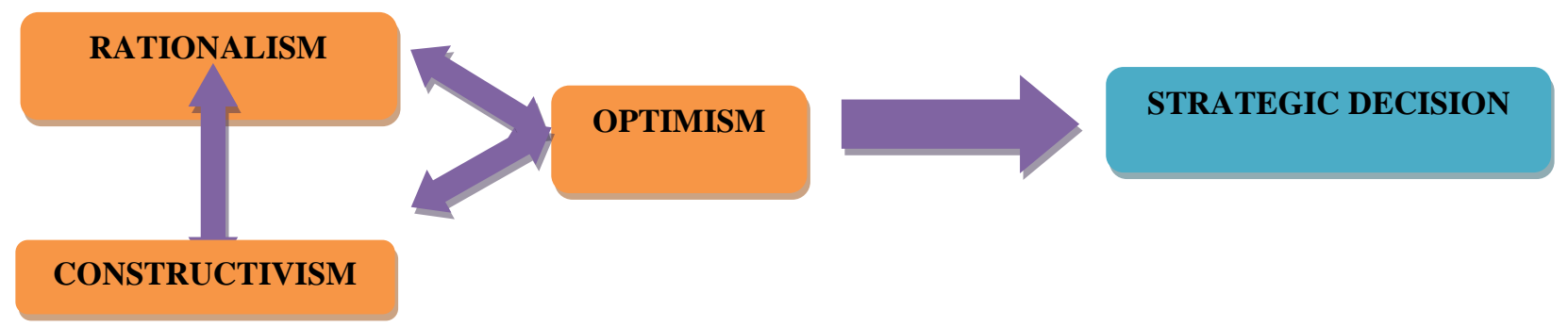

(Multidimensional ROC Model for Strategic Decision Making)

The next three sections of the paper discuss three areas where there are critical interconnections between the paradigms. Although there are theoretical differences, they cannot be overstated since there are considerable overlapping and convergences. The empirical cases can only be explained by a synthetic view of the theoretical constructs.

\section{Materialism versus Idealism}

In traditional IR theory rationalist-constructivist divide is often framed in terms of the former being represented by material factors and the latter being about ideas. The main proposition here is that while rationalism believes that people are always acting on the basis of material self-interest, constructivism believes that people are always acting on the basis of norms and values (Fearon and Wendt, 2002).

Materialists consider that the most fundamental fact about society is the nature and organization of material forces which are broadly classified into five categories (Wendt, 1993, p.23). These material forces can influence real world in various ways such as by facilitating manipulation of the world, by making some actors more powerful than others, by motivating people toward aggression, by causing threats, etc. Importantly, although materialists do not preclude ideas also having some effects, they claim that the effects of such non-material forces are at best secondary. In contrast to materialist views, idealists believe that the most fundamental fact about society is the nature and structure of social consciousness which represents the distribution of ideas or knowledge (Wendt, 1999). Social structure can affect in various ways such as by constituting identities and interests, by assisting actors to find common solutions to problems, by outlining expectations for human and state behavior, by constituting threats, etc. Importantly, although these ideational effects do not deny the role of material forces, idealists claim that material forces are at best secondary.

While the distribution of material forces matters in explaining the dynamics of international system, the main point here is how it matters depends on whether the actors are friends or enemies thereby essentially reflecting the function of shared ideas. It is absolutely imperative to take cognizance of the fact that modern constructivist scholarship emphasizes on social construction in a way that combines tenets of "systemic-level behavior" as well as "macro and micro-levels" linkages together in synergy (Bertucci, Hayes, James, 2018, p.12). Speaking in the context of shared ideas, relationship network is one of the integral components that behavioral scholars consider in the paradigm of cognitive and attitudinal traits. Political leaders' mental disposition and a sense of positive thinking create an impeccable impact in strategic decision process especially when outstanding issues in IR dimensions are being negotiated. Simultaneously, ideas are critically important determinants in government decision making process and policy initiative. Ideas impact policy making when the principled or causal beliefs they represent provide 
road maps that enhance political actors' clarity about policy goals, ends-means relationship, and affect outcomes in strategic situations (Goldstein and Koehane, 1993). These traits are emphasized by behavioral experts in a significant manner while charting out cognitive nature of political actors.

According to the rationalist framework, preferences and expectations generate behavior. This rationalist view is an intentional explanation which is represented by the equation "Desire + Belief $=$ Action" (Wendt, 1999, p. 115; Fearon and Wendt, 2002, p.59). The belief system of an actor is a psychological attribute which when is inclined with positive emotions and engagement leads to positive tangible outcomes. Rationalism treats desire (preference or interest) and belief (expectations or ideas) as distinct variables. This rationalist approach suggests that desires (or interests) do not depend on beliefs and are essentially material. Simultaneously, interest can and ought to be connected with a sense of purpose of the given agenda, often resulting in positive outcome and crisis management.

However, this approach does not ask where interests come from. This leaves an open question as to whether interest is a material or an ideational concept. This missing link is covered by the constructivist framework where constructivism and optimism define the contours of idealism. In actuality, only a small part of what constitutes interests is material. The material force that constitutes interests is human nature. The rest is ideational comprising schemas and deliberations that are in turn constituted by shared ideas or culture. This means that at its core the level of individual choice is essentially guided by ideas and cognitive beliefs (Fearon and Wendt, 2002). Such an interpretation also suggests that materialism has a strong subjectivist aspect thereby emphasizing its affinities to idealist ontology (Wendt, 1999). There is a growing body of scholarship in philosophy and cognitive psychology which argues that desire (preference or interest) is not separate from belief (expectations or ideas) but constituted by it. The cognitive basis of desire argues that desires or interests are themselves cognitions or ideas. Cognitive psychology argues that motivations, desires, or interests should be considered as "schemas which are knowledge structures that make possible the identification of objects and events" (Wendt, 1999, p.122). These schemas are simply beliefs or ideas about the world and drive action.

There is a deep sense of purpose and engagement that is driven by attitudinal attributes of political actors in strategic decision process. In other words, it is the perception of value in an object that motivates action to pursue it. Such perceptions are learned through ideational forces of socialization to culture. In addition to the cognitive psychological interpretation, the deliberative interpretation argues that reason or deliberation should be considered a third factor in the intentional equation to explain action. Although the rationale for looking at a third factor is derived from rational choice theory, if we go deeper into the issue we find that the concept of reason is not independent of beliefs or ideas because it helps to choose interests, determine the feasibility of certain actions, and even about right and wrong (Wendt, 1999). Such inter-connections between reason and beliefs are also discussed in the philosophical literature. The overlap between cognitive and deliberative arguments implies the relationship between interests and ideas - "interests are beliefs about how to meet needs" (Wendt, 1999, p.130). In contemporary political process, positive emotions of political leaders coupled with a sense of optimism resonate the linkage between rationalism and constructivism. This analysis therefore essentially implies that rational choice theory has compatibility with a constructivist view of interests and behavioral attributes of political actors in strategic decision process interprets such convergence in a meaningful manner.

Rationalism in its various forms - realism and liberal institutionalism - assumes that self-interested actors maximize their utility subject to constraints. In rationalist models, preferences and causal beliefs of actors are given. Ideas are relegated a minor role. However, this approach grossly understates the critical significance of ideas in shaping interests, relationship network and positive engagement with regard to policy preferences. In reality ideas matter a lot even when actors behave rationally to achieve their goals. Actions taken by human beings depend a great deal on the "substantive quality of available ideas, since such ideas help to clarify principles and conceptions of causal relationships, and coordinate individual behavior" (Goldstein and Koehane, 1993, p.5). The impact of ideas in the form of causal beliefs lays down the road map while identifying strategies for the attainment of goals. Once ideas get institutionalized in the decision-making process, they continue to guide future actions as well. Moreover, specific policy shifts can be meaningfully traced to changes in the causal beliefs, particularly when the cognitive knowledge is 
simultaneously expanding. Such cognitive belief characterization is impacted by the level of positivity, relationship network and engagement. When political actors negotiate, their personality traits and behavioral aspects are reflected by their innate mental predisposition, which when driven by positive ideas and emotions can result in successful tangible outcome. Therefore, it is important to analyze that public policy, in reality, is constrained because of the "available set of ideas, choices from that set, or bias that prevailing ideas exert on the range of acceptable future policies" (Goldstein and Koehane, 1993, p.13). The direction of government policy can significantly change by ideas in the event of new ideas emerging as a result of changes in underlying conditions of strategic interaction affecting the impact of the existing ideas. Very often the strategic interactive situations are influenced by political actors' behavioral and attitudinal perspectives. On similar lines dynamics of strategic decision process in increasingly interconnected world cannot be properly appreciated without considering cultural, behavioral and ethical perspectives that, in turn, influence the moral dimensions of decision outcome (Gray, 2016). Thus, policy outcomes can be truly explained only when actors' interests and power are combined with a proper understanding of ideational forces. Hence, materialism and idealism cannot be meaningfully discussed in two water-tight compartments without appreciating the critical inter-linkages and points of convergence. Under conditions of uncertainty and incomplete information, innovative inter-subjective ideas, which tend to converge because of actors' trust and positive feeling, can act as roadmaps indicating how they can influence the interests of rational actors and eventually impact the policy outcomes (Risse, 2000). The following case, which discusses the importance of monetary policy in the post-World War II economic settlement, provides an example of how causal beliefs and ideas about the functioning of economy shaped strategic choices of the leaders of the United States and Britain thereby influencing policy outcomes.

After the World War II the construction of an open world economic order by ratifying the Bretton Woods agreements is a glaring example which justifies the basic argument of the critical convergence between materialism, idealism, trust and constructive engagement under the broader perspective of rationalist-constructivist debate. Here behavioral perspectives of world leaders in the crucial meeting in Bretton Woods also influenced the landmark decisions leading to reconstruction of Europe, thereby promoting mutual cooperation between USA and Europe. In the entire political process, leaders of USA and UK were deeply involved in the politico-economic reconciliation because of their positive mental valence and trust that, in turn, culminated in the form of a grand alliance even observable till date. The Anglo-American agreements "established rules for a relatively open and multilateral system of trade and payments but did so in a way that would reconcile openness with the commitments of national governments to full employment and economic stabilization" (Ikenberry, 1993, p.57). In spite of a shift in relative power positions between Britain and the United States, an innovative reconciliation in the post war Anglo-American agreement was engineered laying the foundation of an open economic system. This remarkable incident cannot be explained simply by the narrow version of interest-based argument under rationalist model. There were some ideational forces under constructivist framework converging with interests and preferences. This is a classic example of understanding the way paradigmatic interpretations of rationalism, constructivism and behavioral pursuits of leaders can shape new and innovative policy ideas that bolstered mutual cooperation between the two governments within the contours of predesigned interests.

Thus, we see new policy ideas influenced governments' conceptions of their interests. A set of policy ideas inspired by Keynesianism was accepted by a group of senior government officials on both sides of the Atlantic. This development was "crucial in defining government conceptions of postwar interests, building coalitions based on mutual trust and engagement in support of the postwar settlement, and legitimating the exercise of American power, particularly as these British and American experts engineered a shift from the contentious trade issues to monetary issues, an area where an emerging middle ground had been created by Keynesian ideas" (Ikenberry, 1993, p.58). These experts by virtue of their "new thinking" and positive emotional valence were instrumental in overcoming political differences between the leaders of Britain and the United States. In effect, these transatlantic groups of policy makers inspired by a common set of policy ideas and shared views, intervened at a critical juncture in postwar history in assisting the American and British political leadership identify their strategic 
interests thereby laying the foundation of a robust postwar politico-economic cooperation. As the World War II was coming to an end, political leadership in Britain and the United States started contemplating about the postwar order. The postwar settlement cannot be meaningfully comprehended just by the basis of underlying power capabilities and national economic interests. In reality the postwar Anglo-American agreement was fostered by the converging ideas articulated by the new thinking of the group of policy experts who broke the existing political stalemate between Washington and London. The new ideas, in an environment of cognitive behavioral convergence and reconciliation by political leaders, provided a way to cut through the old cleavages by "pointing to a new set of rules and institutions that could provide an open and multilateral trade and monetary system while also safeguarding national economic autonomy"(Ikenberry, 1993, p.81). There were elements of rationalism, constructivism, and optimism all amalgamated in the strategic decision process, culminating in the birth of a new world economic order that was profoundly characterized by a sense of mutual trust and a spirit of mutual cooperation. These new ideas transformed the strategic policy choice space acceptable to the respective political leadership on both sides of the Atlantic in a way that resulted in political reconciliation and compromise. In effect, the Bretton Woods agreements articulated a middle ground between an unregulated open system and regional or national capitalist arrangements.

Thus, policy ideas provided opportunities for new coalition of strategic interests under a multilateral setting. In a way the example of postwar Anglo-American economic settlement suggests that policy ideas and positive attitudinal alignments of political leaders matter because they provide opportunities for leaders to pursue their strategic interests and preferences in more effective manner.

The empirical case discussed above illustrates that much of the explanatory power of apparent materialist explanations is actually constituted by latent constructivist and behavioral assumptions about the generation, content and dissemination of ideas. In other words, the meaning and content of interests are essentially a function of ideas. Therefore, it is appropriate to argue that the concepts of materialism and idealism within the broader canopy of rationalist-constructivist debate cannot be meaningfully explored without integrating the cognitive and behavioral characterizations of leaders so much so that they might even bring in an unexpectedly positive outcome in a much expeditious manner. It is essential to take cognizance of the fact that in contemporary international politics tenets of rationalism, constructivism and optimism are intertwined in a synthetic view to appreciate their true meaning and implications.

\section{Logic of Consequences versus Logic of Appropriateness}

Rationalism-constructivism debate in IR is often interpreted in terms of the contrast between logic of consequences and logic of appropriateness. The logic of consequences is the realm of rationalist approach that treats the interests and preferences of actors as given and fixed during the process of interaction. Rationalists focus on strategic interactions in which agents participate based on their given identities and interests. Through this process rational actors as egoistic utility maximizing agents try to realize their preferences through strategic behavior. This is the "realm of instrumental rationality whereby the goal of action is to maximize or optimize one's own interests and preferences" (Risse, 2000, p.3). Logic of consequences is instrumental and subscribe to utility-maximizing action that is guided by the outcome of action. Actions are considered as efficient means to transmit into positive outcome. In consequential logic, political order is considered as arising from negotiations among rational actors pursuing personal preferences and interests. Where coordination is achieved to maximize the strategic gains, the terms of such coordination depend on the bargaining position of the rational actors (March and Olsen, 1998). In the context of contemporary multilateral architecture in international politics, rationalist approach necessarily needs to imbibe elements of behavioral optimism of political leaders in strategic decision process in order to arrive at a mutually agreeable meaningful outcome. Despite "principled and causal beliefs can enter the utility functions of actors, affect cost-benefit calculations, and influence the strategic interactions themselves," nevertheless such cost-benefit calculations at the time of negotiation process are highly incumbent upon the positivity and constructivist mindset of leaders to settle outstanding political disputes. On similar lines, researchers of modern constructivism, while making significant interface with tenets of positivity and optimism, have developed a theoretical apparatus that is intended to capture the 
nature of the norm lifecycle. At the epicenter of this theoretical construct is human action imbued with positivity, that attempts to make a synergy between the logic of appropriateness and that of consequences (Wagner, 2014).

In contrast, social constructivists subscribe to the logic of appropriateness which essentially characterizes political leaders to follow rules that associate particular identities to particular situations. Logic of appropriateness advocates "rule-guided behavior" which differs from instrumental rational behavior in the sense that actors try to do the appropriate (right) thing rather than maximizing or optimizing their given preferences (Risse, 2000, p.4). Normative principles are socially constructed, and the rules not only regulate behavior or have causal effects, but also define social identities. Thus, social constructivism puts forward the constitutive role of ideational factors. Socially shared ideas in their intersubjective role in IR domain not only emphasize collective norms and understandings constituting social identities of political actors but also outlay the basic rules which regulate actors' behavior in social interaction. Here one can decipher the convergence between behavioral traits and alignment of ideational forces, which might further propel the diplomatic contours of political leadership in strategic decision process. In reality, the pursuit of purpose is associated more with identities than with interests and also with the selection of rules more than with individual rational expectations (March and Olsen, 1998).

The paper argues that although there is a general tendency to divide the consequential and appropriateness propositions into separate spheres, the former primarily based on calculations of expected consequences and the latter based on rule guided behavior, the two are not mutually exclusive in real sense. Political actions are complicated and cannot be rooted to exclusively in terms of logic of either consequences or appropriateness. Any particular action has to involve elements of each in some way or the other. Hence it is technically and theoretically inappropriate to discuss the two in two separate compartments. Although political actors make choices based on calculated expected consequences, some choices are tightly constrained by existing norms and rules which are socially constructed. Again in some settings "the problem of figuring out what to do seem to entail primarily the interpretation and application of conflicting normative claims, rather than establishing the likelihood that such-and-such action will lead to such-and-such result"(Fearon and Wendt, 2002, p.60). Political and business actors calculate consequences and follow rules (March and Olsen, 1998). The synergy between the two mainstream IR paradigms is further strengthened by optimism, behavioral and attitudinal dimensions of political leaders. Thus, the relationship between the various theoretical constructs is delicately intertwined and finely woven.

The third interpretation for the relationship is based on development practices. It means that once the consequence-based rational instrumental action gets more rule-based in a specific situation, the accumulated experience also increases. In such a situation, "rules and standard operating procedures supplant and constrain instrumental-calculative action in a given situation as a result of experience" (March and Olsen, 1998, p.953). Consequently, instrumental mode of action can get self-limiting while rule-based mode self-reinforcing, which can be further propelled by behavioral synergy of leaders in strategic political decision process.

The following case can be meaningfully explained on basis of the relationship between the consequential and appropriateness interpretations. The case deals with eastern enlargement of the European Union after the collapse of the Soviet bloc. Rationalist argument based on the tenets of logic of consequences can explain the association of Central and Eastern European countries with the EU. Here the given interests and preferences of western European countries based on material capabilities asymmetry would lead the bargaining process in their favor. However, this rationalist argument fails to account for the European Community's decision to go beyond mere economic association and offer the five Central and Eastern European countries full membership of the EU (Schimmelfennig, 2001). The logic behind the membership issue, which far more exceeds the association issue, can only be meaningfully explained with a sociological perspective in which membership is considered as an enlargement and eastward expansion of the EU. If the EU is considered as the organization of the European liberal community of states, its decision to initiate accession negotiations with five Central and Eastern European countries can be regarded as the inclusion of those countries that would share the same liberal values and norms. The main 
point here is to explain how a rational outcome in the form of association based on egoistic preferences and relative bargaining power was converted into a normative outcome in the form of enlargement. This can be answered by the proposition of "rhetorical action - the strategic use of norm-based arguments - as the intervening mechanism" (Schimmelfennig, 2001, p.48). Any account of the EU's decision-making process on eastern enlargement must reconcile and causally link the two logics - consequential based on rationalist theory and appropriateness based on constructivist theory. This reconcilement and establishment of missing link between self-interested western European states' association preferences based on material conditions and distribution of material bargaining power, and the eastern enlargement of the EU based on the principle of collective identity and socially shared norms of an international community is essential to deliberate the final outcome of providing EU membership to the five Central and Eastern European countries. This was essentially possible by a meticulous effort of building relationship network coupled with optimism and engagement among political leaders involved in strategic decision process. In the institutional setting of the EU, the proponents of enlargement were able to justify their preferences on the grounds of the EC's traditional philosophy of pan-European liberal constitutive norms and values, thereby overcoming and forcing the opponents to fall in line with enlargement. By normatively "entrapping" the opponents of EU's commitment to Eastern enlargement the proponents of EU enlargement, through the process of "rhetorical action" which essentially entailed the strategic use of norm-based arguments coupled with political relationship management and confidence building measures were able to bring about a collective outcome, based on socially constructed normative principles, that would not have been expected only by the rationalist perspective of the constellation of power, interests, and asymmetric bargaining process (Schimmelfennig, 2001, p.76-77). This discussion of strategic use of normative arguments is based on "manipulative, instrumental understanding of persuasion," which is essentially propelled by optimism and sincere political engagement (Checkel and Moravcsik, 2001, p.221). The case illustrates how elites in Eastern Europe were manipulating the EU's own professed values and norms to accelerate the enlargement process. The normative criterion of persuasion had causal effect which ultimately entrapped the EU policymakers in their own rhetoric, leading to desired outcome of EU enlargement in an amicable manner.

\section{Exogenous versus endogenous actors, interests, and preferences}

Another major issue in the rationalist-constructivist debate is whether to treat actors, their interests and preferences as exogenous or endogenous. Rationalists tend to treat actors and their preferences as exogenously given whereas constructivists try to endogenize them. This paper argues here that such a distinction is difficult to sustain in a hard and fast form. Especially in empirical analysis, the two views cannot be discussed separately since there are significant inter-connections between the two. Hence, it is not advisable to treat the two views in separate spheres just on narrow superficial perspective. On the contrary it is always prudent to treat the rationalists-constructivists views together by a synergy between behavioral optimism and attitudinal perspectives of political actors in order to appreciate the theoretical as well as empirical observations.

First, treating actors and their preferences simply as exogenously given has theoretical and political complications. It matters theoretically because assumption of exogeneity implicitly makes an empirical claim about the world in the sense that what actors want is constant and stable within the context of the study (Fearon and Wendt, 2002). If this claim is not accurate then the causal implications on actor's behavior will be problematic. It matters politically because if what actors want cannot be made stable, then the policy outcomes based on the assumption of stability may not have desired effect and may understate the prospects of socio-political change. Since in reality rationalists' claim of stability of world politics is questionable and a matter of conjecture, it is empirically difficult to accept the validity of the proposition that exogenously given preferences are really stable for all times. Hence, constructivists argue in favor of endogenizing identities, ideas and interests. This is because if it can be shown that the process of social interaction creates interests and preferences, then it will depict a more accurate picture of potential socio-political change. In order to reduce the chances of transformation of analytical assumptions of stability of world politics into tacit ontological claims, it is always prudent to address rationalists and constructivists views in a coordinated fashion rather than going in separate ways, since 
the behavioral synergy of politico-economic actors based on mutual trust is absolutely imperative in strategic decision process (Fearon and Wendt, 2002).

Second, with regard to materialist-idealist divide within the broader perspective of rationalistconstructivist debate, the exogeneity and endogeneity of political actors and their interests cannot be explained in two separate spheres. Interests cannot be seen as just exogenously given. Rather what matters is where do interests come from, how they evolve, and how they are thought to be constituted. Only a small part of what constitutes interests is actually material. The material force constituting interests and preferences is human nature, anarchy, self-help and distribution of power resources. These material elements are exogenously given. The rest is ideational - schemas and deliberations that are in turn constituted by shared ideas or culture that are generally endogenous characteristics (Wendt, 1999). In reality, modern theorists stress upon diplomatic endeavors as reciprocal forces reinforcing each other in a relational manner. In this context strategic decision making, irrespective of exogeneity and endogeneity, in effective diplomacy is generally perceived as a system of reciprocal signaling, thereby focusing on interrelated and connected nature of international politics (Adler-Nissen, 2015). Here again optimism and behavioral alignment coupled with engagement of political leaders essentially reinforce ideational sharing of views in a multicultural diplomatic architecture.

Third, cultural accounts and rationalist two-step model (preferences and interaction) need not be mutually exclusive. There is an important overlap between cultural and rational analysis. The concept of organizational culture is defined as collectively held assumptions, ideas, and beliefs that prescribe how a group should adapt to its external environment and manage its internal structure. At the same time there is significant complementary effect between exogeneity and endogeneity of preferences in the decisionmaking process, stimulated by cognitive associations propelled by confidence building among political leaders. This is possible by overlapping the "utility of collective beliefs and habits in the context of standard economic two-step framework of preferences and interaction" (Wendt, 1999, p.118-119). Hence, the organizational culture approach asserts that the beliefs and customs embedded in political leadership in coordination with external circumstances can determine desired positive outcomes in strategic decision process. The following empirical case involving British strategic bombing over Germany during World War II in 1940 illustrates how organizational cultural dimensions were so much influential in that surprise attack by Britain even in the face of air-power asymmetry heavily in favor of Germany. The case exemplifies that simply the notion of exogenous preference formation without involving endogenous forces is not sufficient to make in-depth analysis of strategic international events. The case illustrates that organizational culture, in coordination with endogenous ideational convergences and external contingencies, matters in preference formation.

\section{Discussion}

Dynamics of contemporary international environment reflect that strategic decision processes are not only complex but also cut across the dimensions of several issues that range from international diplomacy, business relations, expansion of business and economic relations into new geographies, bilateral and multilateral politico-economic architecture and finally the mental predisposition of leaders or actors who are involved in such process. In an ever-changing framework global interdependence, an optimal synergy between the fundamental tenets of Rationalism, Constructivism and Optimism is going to be absolutely crucial in determining the outcome of decision process. Importantly, the multidimensional ROC Model introduced in this paper provides a solid foundation to the process of making meaningful synergy in a classic interdisciplinary nomenclature where mainstream theories can work in tandem with each other realistically. Our ROC Model assists in identifying convergences between diverse groups and affiliations that are involved in strategic political, economic and business decision making in regional and extra-regional geographical contours. The empirical analysis enshrined in the paper fully corroborates the practical implications of ROC Model. Also the current dynamics pertaining to political and business alliance formation, efforts to forge new business partnerships, attempts to make meaningful long-lasting positive solutions/outcome to outstanding global problems ranging from climate change, technology transfer, global economic and business developments with equitable distribution of income and wealth, issues, terrorism, cyber-security and trade related complex issues can be effectively 
dealt with by applying the fundamental spirit of multidimensional ROC Model, which essentially provides the framework of identifying convergences amidst divergences.

\section{Recommendations and Policy Implications}

The present study that introduces multidimensional ROC Model provides a well-structured theoretical framework whose application is highly recommended in exploring much needed synergy in policy formulation and implementation. The policy implications of the study are broad in versatile enough encompassing complex issues across different disciplines in contemporary international environment. To be specific, the study and the ROC Model framework are recommended in addressing the following aspects:

Outstanding trade problems between the developing and developed countries have been stalling the negotiation process of WTO ministerial conferences in recent years. There are significant differences between the nations related to complex issues such as agricultural subsidies, technology transfer, intellectual property rights, etc. Yet, these issues can be meaningfully addressed in a phased manner by applying the fundamental tenets of ROC Model that seeks synergy between the paradigms of rationalism, constructivism and optimism while finding convergence of interests in strategic decision process, especially in a multilateral system of interdependence. The positive attitude of leaders in the process can act as catalytic force in layering the issues related to rationalism and constructivisms, thereby making successful negotiations happen.

With regard to domestic tax policy, a classic practical implication of this study can be found in the formulation and implementation process of Goods and Services Tax (GST) in India since July 2017. GST is regarded to be the most prolific structural economic intervention in India since the country's independence. GST has transformed the entire indirect tax regime in India in a manner that is unprecedented and extremely productive. The politico-economic run up to the debate and subsequent formulation of GST in a classic multi-party parliamentary democratic system is perhaps the most vivid example the world has ever witnessed, while making efforts in finding convergences across partisan and ideological divide in political and business establishments. The policy by itself inculcates the spirit of "cooperative-federalism" in which the central and state governments are equal partners in the decision process with regard to rationalization of tax structure of GST policy and its optimal implementation (Bhattacharjee and Bhattacharya, 2018).

The formation of various trade blocs, especially the European Union and its expansion to include eastern European countries after the collapse of the erstwhile Soviet Union also satisfies the fundamental spirit of ROC Model. The policy implications of the study are clearly observable when partisan and ideological divides were overcome by forging convergences in order to promote business under the framework of regional trade agreement. Simultaneously the complex process of currency union by effective formation and implementation of Euro exemplifies how synergy between diverse perspectives and priorities can be effectively crystallized in business policy formulation.

The politico-economic grouping called BRICS comprising Brazil, Russia, India, China and South Africa provides policy implication of ROC Model in international environment. Here diverse groups of countries belonging to different geographies forge an effective alliance for primarily promoting economic and business development in the grouping. The formation of New Development Bank (NDB) specifically formed for BRICS economic development and IBSA (India-Brazil-South Africa) dialogue are important dimensions of policy implications in international environment. Such policy frameworks promote business expansion and exchange of managerial leadership skillsets within BRICS community for reaping the benefits of shared prosperity in an inclusive manner. Importantly, notwithstanding the diversities, the specific implications of the study enshrined in this research paper are evident in promoting sharing managerial talent, business alliance, foreign direct investment, and people to people contact. The initiative of Fourth Industrial Revolution as decided in 10th BRICS Summit in Johannesburg in July 2018 in the domain of digitalization is promoted by BRICS community in the spirit of business and managerial development while establishing commercial linkages in an inclusive manner.

Further, the fundamental logic of the study in this paper are recommended in various political and business policy implementation processes related to Israeli-Arab tensions; US-North Korea diplomatic 
endeavors; India-China strategic political and business dialogue especially to effectively tackle the complex issues related to the Line of Actual Control; Technology transfer issues related to clean energy and their business implications in the broader framework North-South cooperation.

\section{Conclusion}

The debate between Rationalism, Constructivism and Optimism, as dramatic as it is, cannot be and must not be misconstrued. A closer empirical investigation brings to the forefront the deeper interconnections between the three constructs - Rationalism, Optimism and Constructivism - that is clearly observable by a deepened convergence as resonated by actions of world leaders. It is important to acknowledge that in reality all these approaches work in tandem with each other and play a complementary role, rather than competing, in answering questions about world politics.

The paper, while examining the three contentious issues of the great debate, has increasingly got motivated by the argument that there is an urgent necessity to go beyond the theoretical cleavages between rationalism and constructivism and associate with optimism that drives behavior including resilience, political engagement coupled with meaningful purpose in order to correctly interpret the empirical cases of political decision process in the ambit of international relations. In addition to the empirical cases analyzed in this paper, such argument get traction if we traverse through the terrain of world political history even as recent as U.S. President Donald Trump and North Korean Supreme Leader Kim Jong-un summit meeting on June 12, 2018 in Singapore. The run up to the summit provides compelling evidence of the multidimensional ROC Model, introduced and stated in this paper, whereby the theoretical constructs of Rationalism, Optimism and Constructivism worked in tandem with each other on both sides, ultimately transpiring into the first ever such kind of a summit in world politics. Similar evidence can be observed when in the peak of the Cold War era then U.S. President Ronald Reagan and General Secretary of the Communist Party of Soviet Union Mikhail Gorbachev got engaged in serious dialogue through three strategic summit meetings at Washington D.C., Moscow, and Reykjavik (Iceland) to diffuse diplomatic and economic tension and signing landmark defense treaty - Intermediate Range Nuclear Force Treaty - between the two superpowers.

Additionally, world political history accounts for other landmark developments that bolster ROC Model. For instance, (i) the historic visit of then U.S. President Barack Obama to Myanmar in November 2012, the first ever by a sitting U.S. President; (ii) the restoration of diplomatic and trade relations between the United States and Cuba, after 54 years of contentious politics, by the visit of President Obama to Cuba in 2016; (iii) the unification of West and East Germany by pulling down the Berlin Wall; are further illustrations that reiterate the overarching theoretical foundation of multidimensional ROC Model introduced and elaborated in this paper.

With all the illustrations analyzed in this paper it is imperative to admit that the narrow scope of zero-sum interpretation between the various approaches is grossly insufficient to explain the decisions and actions taken by political leaders, states, international institutions etc. This is because such interpretations fail to engage in broader inter-subjective analyses that cut across the rationalistconstructivist-optimism boundary. In each of the empirical cases examined in this paper the assumptions and narrow scope of theoretical divide between the three 'isms' fail to explain the dynamics behind the decisions made by global leaders and resultant outcomes. Instead a synthetic view of multiple and eclectic approaches, highlighting the inter-connections and inter-subjectivity of the contexts, is necessarily imperative to meaningfully explain them. It is pertinent to take advantage of the benefits derived by synthesizing the multidimensional implications of paradigmatic approaches in politico-economic and business domain. Deliberations in this paper profoundly confirm this proposition of deep underlying interconnections and reciprocity between the three theoretical constructs.

\section{Limitations and Future Directions}

This study focuses in creating layering, the so-called convergence, between mainstream tenets of Rationalism, Constructivism and Optimism primarily in an international framework. While doing so, the study might have missed out some contingencies that are involved in domestic political and business dimensions as far as policy formulation and implementation are concerned. Also, as part of future 
research agenda the scope of the study can be specifically extended to pressing global problems that affect the general economic and technological wellbeing of majority of population in order to usher in an era of shared prosperity with inclusiveness. In this context the authors believe that optimal trade-off between domestic politico-economic environment and international environment will be pertinent.

The authors envisage that future research can focus on application of ROC in addressing complexities and divergences in legislative-executive relations in policy formulation and their implications in domestic political and business environment of different countries. In this context an interesting comparative analysis can be made by exploring the study implications in parliamentary democratic system such as India, the UK, Australia, Canada, etc. on one hand and separated system such as the United States on other hand. The cross-sectional dimensions of the two systems in domestic policy formulation and implementation will make ROC framework more versatile in its nature and extent. As examples, further in-depth exploration of constantly evolving Goods and Services Tax (GST) formulation and implementation in India since 2017 and Affordable Health-Care Act since 2010 in the United States can be taken up as future research agenda to examine the specific implications of the study.

The authors would also like to suggest that future research can further concentrate on meticulous investigation of changing dynamics of rationalism and constructivism in contemporary context while assessing the level of synergy of highly abstract nature of complex psycho-dimensional behavioral traits of leaders/actors in complex strategic decision process, especially in the context of domestic business policy formulation.

Another interesting area for future research is to ascertain study implications of ROC framework in understanding the symbiotic relationship between influential business circles and powerful special interests in formulating specific policies that serves the dynamics of interest group politics. This research area is more profoundly applicable to the nature of policy decision process commonly witnessed in developed countries. Nevertheless, its implications can be distinctly felt in complex trade negotiations especially at the ministerial conferences of the World Trade Organization. The level and intensity of synergy between rationalist perspective, constructivism and optimism related to high profile issues like environment, climate change, agriculture, clean energy technology are critical areas of future research agenda. Also, the trade-off between the issues related to "logic of consequences" and "logic of appropriateness" can be studied as part of future research agenda.

\section{References}

Adler-Nissen, R. (2015). Conclusion: Relationalism or Why Diplomats find International Relations Theory Strange. Diplomacy and the Making of World Politics, pp. 284-308.

Banerjee, P. (2018). The Power of Positivity: Optimism and the $7^{\text {th }}$ Sense. New Delhi, India: SAGE Publications.

Bertucci, M.E., J. Hayes, and P. James. (2018). A New Look at Constructivism. In M.E. Bertucci, J. Hayes, and P. James, ed., Constructivism Reconsidered: Past, Present and Future, Ann Arbor: University of Michigan Press.

Bhattacharjee, G. and D. Bhattacharya. (2018). GST and Its Aftermath: Is Consumer Really the King? New Delhi, India: SAGE Publications.

Checkel, J.T. and A. Moravcsik. (2001). A Constructivist Research Program in EU Studies. European Union Politics, 2, pp. 219-249.

Fearon, J. and A. Wendt. (2002). Rationalism v. Constructivism: A Skeptical View. In: W. Carlsnaes, T. Risse, and B.A. Simmons, ed., Handbook of International Relations. London, Thousand Oaks, New Delhi: SAGE Publications.

Finnemore, M. and K. Sikkink. (2001). Taking Stock: The Constructivist Research Program in International Relations and Comparative Politics. Annual Review of Political Science, 4, pp. 391-416.

Finnemore, M. (2003). The Purpose of Intervention: Changing Beliefs about the Use of Force. Ithaca and London: Cornell University Press.

Goldstein, J. and R.O. Keohane. (1993). Ideas and Foreign Policy: An Analytical Framework. In: J. Goldstein and R.O. Keohane, ed., Ideas and Foreign Policy: Beliefs, Institutions, and Political Change. Ithaca and London: Cornell University Press.

Gray, C.S. (2016). Strategy and Politics. London: Routledge.

Haukkala, J., C. Watering and J. Vuorelma (2018). Introduction: Approaching Trust and Mistrust in International Relations. In: J. Haukkala, C. Watering and J. Vuorelma, ed., Trust in International Relations: Rationalists, Constructivists and Psychological Approaches. Abingdon, Oxon, New York: Routledge. 
Hurrell, A. and T. Macdonald. (2013). Ethics and Norms in International Relations. In: W. Carlsnaes, T. Risse, and B.A. Simmons, ed., Handbook of International Relations (Second Edition). London, Thousand Oaks, New Delhi: SAGE Publications.

Ikenberry, J. G. (1993). Creating yesterday's New World Order: Keynesian New Thinking and the Anglo-American Postwar Settlement. In: J. Goldstein and R.O. Keohane, ed., Ideas and Foreign Policy: Beliefs, Institutions, and Political Change. Ithaca and London: Cornell University Press.

Legro, J.W. (1996). Culture and Preferences in the International Cooperation Two-Step. American Political Science Review, 90, pp. 118-137.

March, J.G. and J.P. Olsen. (1998) The Institutional Dynamics of International Political Orders. International Organization, 52, pp. 943-969.

Risse, T. (2000). Let's Argue! Communicative Action in World Politics. International Organization, 54, pp. 1-39.

Schimmelfennig, F. (2001). The Community Trap: Liberal Norms, Rhetorical Action, and the Eastern Enlargement of the European Union. International Organization, 55, pp. 47-80.

Stein, A.A. (1999). The limits of strategic choice: Constrained rationality and incomplete explanation. In: D.A. Lake and R. Powell, ed., Strategic Choice and International Relations. Princeton, NJ: Princeton University Press.

Wagner, W. (2014). International Relations and Human Rights. In: A. Mihr and M. Gibney, ed., The SAGE Handbook of Human Rights (Volume 1). London, Thousand Oaks, New Delhi: SAGE Publications.

Wendt, A. (1999). Social Theory of International Politics. Cambridge, UK; New York: Cambridge University Press. 